06

\title{
Исследование транспорта кислорода в структурно-модифицированных электродах методом вращающегося дискового электрода
}

\author{
(C) Н.В. Глебова, А.О. Краснова, А.А. Нечитайлов \\ Физико-технический институт им. А.Ф. Иофрфе РАН, \\ 194021 Санкт-Петербург, Россия \\ e-mail: glebova@mail.ioffe.ru
}

Поступило в Редакцию 30 декабря 2020 г.

В окончательной редакции 3 февраля 2021 г.

Принято к публикации 6 фревраля 2021 г.

\begin{abstract}
Методами дискового вращающегося электрода исследованы особенности переноса молекулярного кислорода в платино-углеродных электродах со смешанной проводимостью, содержащих структурно-модифицирующие добавки со структурными элементами различного типа: короткие и длинные углеродные нанотрубки, имеющие вытянутые структурные элементы с различным отношением длина/диаметр, и графеноподобные материалы с практически двумерными плоскостями.
\end{abstract}

Ключевые слова: графеноподобные материалы, дисковый электрод, углеродные нанотрубки.

DOI: 10.21883/JTF.2021.07.50956.354-20

\section{Введение}

Как известно, массоперенос вносит существенный вклад в энергетические потери в электрохимических электродах, к которым относятся объекты, исследованные в настоящей работе. Перенос вещества, наряду с переносом зарядов и реакции разряда на поверхности электрода, составляет один из основных процессов, определяющих скорость электрохимического процесса и эффективность работы электрода [1]. В связи с этим поиск и исследование путей и механизмов уменьшения массотранспортных потерь в электрохимических системах остается актуальной фундаментальной и практической задачей. Исследуемые в работе закономерности имеют значение для широкого круга электродных материалов, электродов на их основе и готовых изделий, таких как электролизеры воды, и других устройств с электрохимическими электродами. В качестве функциональных добавок в электроды по нескольким причинам представляют особый интерес углеродные наноструктурированные материалы. Они имеют низкое электрическое сопротивление переносу электронов и не создают дополнительных резистивных потерь; эти материалы довольно коррозионно-стойкие как при электрохимическом (химическом), так и при термическом воздействии; они не продуцируют ионов и не блокируют тем самым ионную проводимость обычно присутствующего ион-проводящего полимера; они обладают уникальным разнообразием форм структурных элементов. В связи с этим такие материалы широко используются в качестве компонентов электрохимических электродов [2-4] и несут на себе ту или иную функциональную нагрузку в качестве, например, носителя электрокатализатора [2], промотирующего каталитические свойства компонента [3], структурно-модифицирующего материала [4].
Рассматриваемые в настоящей работе электроды представляют собой пористые композитные структуры, содержащие наночастицы платины на углеродной саже, протонпроводящий полимер типа Nafion и добавку того или иного углеродного материала в качестве структуририрующего компонента. Такие электроды нашли широкое применение в кислородно-водородных топливных элементах и электролизерах воды. Диффузия молекулярного кислорода в этих структурах, в силу его относительно (по сравнению с водородом) небольшой подвижности, как правило, определяет массотранспортные потери. Для сравнения эффективности тех или иных функциональных добавок в плане массопереноса необходимо исследовать перенос вещества (кислорода) в рассматриваемых структурах.

Метод дискового вращающегося электрода (ДВЭ) широко применяется при изучении электрохимических процессов как в растворах, так и в пористых средах, нанесенных на поверхность электрода. Метод дискового электрода является мощным инструментом, позволяющим исследовать электродные материалы $[5,6]$ и различные стадии электрохимического процесса.

Цель настоящей работы состояла в получении экспериментальных данных, полученных методом дискового электрода, о влиянии добавок различных наноструктурированных углеродных материалов в электрод на особенности переноса кислорода в полученной структуре.

\section{1. Теория}

\section{1. Измерение диффузионного тока в электродах топливных элементов}

Наибольшее распространение при экспериментальном исследовании массотранспортных потерь получили два 
подхода, основанные на сравнении напряжения элемента во время работы с кислородно-гелиевой средой $(79 \% \mathrm{He,}$ $21 \% \mathrm{O}_{2}$ ) или чистым $\mathrm{O}_{2}$ [7-9] и метод, основанный на измерении плотности предельного диффузионного тока $[10-12]$. В первом подходе использование коротких промежутков времени $(2 \mathrm{~s})$ позволяет исключить влияние высыхания или изменение степени окисления поверхности катализатора, связанные с непрерывной работой с этими газами, однако получаемые при использовании этого метода результаты не отражают диффузионные свойства в процессе функционирования электрода. Второй подход позволяет получать данные о диффузионных свойствах электрохимической системы при реальных и различных условиях функционирования (влажность газов, давление газов, условия продувки анода и др.).

В настоящей работе использован подход, основанный на измерении плотности предельного диффузионного тока методом ДВЭ, подробно описанный в нашей работе [13].

Метод ДВЭ при применении его для раствора электролита (серная кислота) обладает рядом сильных сторон. Во-первых, благодаря раствору электролита, протонная проводимость электродов различного состава приводится к близким относительно друг друга величинам за счет пропитывания электрода электролитом. Во-вторых, поры практически полностью затоплены раствором электролита, в результате чего диффузия в них зависит только от их морфологии, так как она происходит в жидкой фазе и не зависит от степени затопления пор. В-третьих, благодаря изменению скорости вращения электрода метод позволяет разделять происходящие процессы: внешнюю и внутреннюю диффузии, электрохимическую реакцию.

Дисковый вращающийся электрод представляет собой диск из проводящего материала, запрессованный (или впаянный) в изолирующую оболочку [14-16]. Электрод приводится во вращение вокруг своей оси при помощи электромотора. При этом жидкость (раствор электролита), соприкасающаяся с центральной частью диска, отбрасывается к его краям, а на его место снизу поступают новые порции. Вблизи электрода образуется пограничный гидродинамический слой равномерной толщины, внутри которого происходит постепенное нарастание скорости движения жидкости от нуля у самой поверхности электрода. Массоперенос вещества в пограничном гидродинамическом слое происходит в результате конвективной диффузии, причем толщина пограничного диффузионного слоя, который лежит внутри гидродинамического слоя и в котором концентрация реагирующего на электроде вещества изменяется от значения $c_{0}$ в глубине раствора до значения $c_{s}$ у поверхности электрода, постоянна в любой точке. Это означает, что вращающийся дисковый электрод равнодоступен в диффузионном отношении (т.е. скорость диффузии одинакова в любой точке поверхности диска). Если скорость реакции на дисковом электроде лимитируется массопереносом, то плотность тока (в отсутствие миграции реагирующих ионов) одинакова по всей поверхности и равна $\left(\right.$ в $\left.\mathrm{A} / \mathrm{m}^{2}\right)$ :

$$
j=0.62 n F D^{2 / 3} \eta^{-1 / 6} \omega^{1 / 2}\left(c_{0}-c_{s}\right),
$$

где $\omega-$ угловая скорость вращения электрода, $[\mathrm{rad} / \mathrm{s}]$, $\eta$ - кинематическая вязкость раствора, $\left[\mathrm{m}^{2} / \mathrm{s}\right], D-$ коэффициент диффузии реагирующего вещества, $\left[\mathrm{m}^{2} / \mathrm{s}\right]$, $n$ - число электронов, участвующих в реакции, $F-$ число Фарадея, $c_{0}$ и $c_{s}-$ концентрации, $\left[\mathrm{mol} / \mathrm{m}^{3}\right]$. Точность формулы - $1-3 \%$. С ростом поляризации электрода концентрация $c_{s}$ падает до нуля, и ток $j$ достигает предельного диффузионного значения $\left(j_{d}\right)$. Дисковый электрод не требует калибровки. Метод дискового электрода применим для процессов, скорость которых лимитируется диффузией; характерный их признак прямая пропорциональность между $j$ и $\omega^{1 / 2}$.

\section{2. Эксперимент}

В настоящей работе экспериментально исследованы плотности предельных токов различных электродных структур, нанесенных на поверхность дискового электрода. Исследованные образцы отличались друг от друга наличием той или иной добавки („короткие“ и „длинные“ углеродные нанотрубки (УНТ), графеноподобный материал).

\section{1. Использованные материалы}

\subsection{1. Платинированная углеродная сажа (Pt/C)}

Использовали коммерческий продукт под маркой E-TEK, содержащий 20 и 40\% платины на углеродной саже типа Vulcan XC-72 [17]. Удельная площадь поверхности составляет 200 [18] $-250 \mathrm{~m}^{2} / \mathrm{g}$ [19-22].

\subsection{2. $y H T$}

Использовали короткие и длинные многостенные УНТ.

\subsection{3. Короткие УНт типа Плазмас}

Использованные в работе УНТ охарактеризованы методами просвечивающей (ПЭМ) (микроскоп типа JEM 2100-F, Jeol, Япония) и растровой электронной микроскопии (РЭМ) (микроскоп типа JSM-7001F, Jeol, Япония), EDX и адсорбционно-структурного анализа по низкотемпературной адсорбции азота (анализатор ASAP 2020 фирмы Micromeritics (США). УНТ Плазмас получены методом дугового разряда между графитовыми электродами в жидкой углеводородной среде [23,24]. Характерная микрофотография материала приведена на рис. 1.

Удельная площадь поверхности УНТ, измеренная по низкотемпературной адсорбции азота, составляла $13 \mathrm{~m}^{2} / \mathrm{g}$. Диаметр трубок колеблется в интервале 


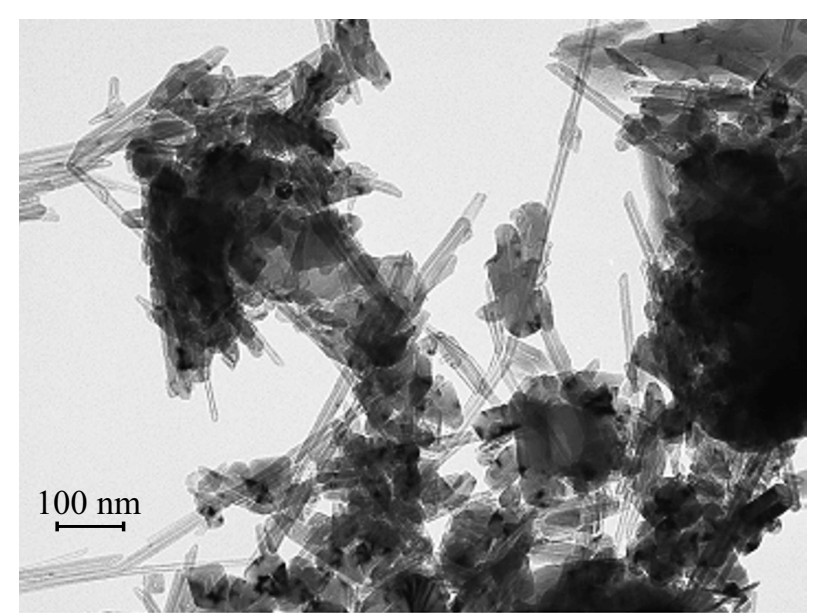

Рис. 1. ПЭМ изображение углеродного наноматериала Плазмac.

Таблица 1. Элементный состав УНТ Плазмас (\%): исходных и после кислотной обработки

\begin{tabular}{l|c|c}
\hline Элемент & Исходные & После обработки \\
\hline $\mathrm{C}$ & 95.1 & 98.9 \\
$\mathrm{O}$ & 1.36 & 0.45 \\
$\mathrm{Al}$ & 2.63 & 0.34 \\
$\mathrm{Fe}$ & 0.94 & - \\
$\mathrm{S}$ & - & 0.29 \\
Сумма & 100.03 & 99.98
\end{tabular}

$12-33 \mathrm{~nm}$. Однако преимущественное большинство имеет диаметр 12-14 $\mathrm{nm}$. Длина 200-300 $\mathrm{nm}$. УНТ подвергали плазмохимической модификации в высокочастотном плазменном разряде в среде аргона с последующей обработкой активированных нанотрубок азотом [23]. При модификации многостенных УНТ в высокочастотной плазме открываются в первую очередь закрытые полусферические концы, вносятся дефекты в поверхностную структуру, открываются внутренние межслойные пазухи, изменяется морфология, пористая структура УНТ [24].

С целью очистки от металлических примесей УНТ обрабатывали раствором азотной кислоты $(1: 1)$ при температуре $\sim 100^{\circ} \mathrm{C}$ в течение $5 \mathrm{~min}$ с последующей многократной промывкой водой и сушкой. Такая обработка приводила к снижению примерно на порядок содержания примесей металлов (табл. 1).

\subsection{4. Длинные УНТ типа Таунит МД}

Использовали многостенные УНТ типа Таунит МД (производство ООО „НаноТехЦентр“, Тамбов) [25]. Характерными структурными свойствами этих нанотрубок являются большое отношение длины к диаметру, составляющее $670-2500$, и высокая пористость за счет пор больше $100 \mathrm{~nm}$ (рис. 2) [26]). УНТ были очищены

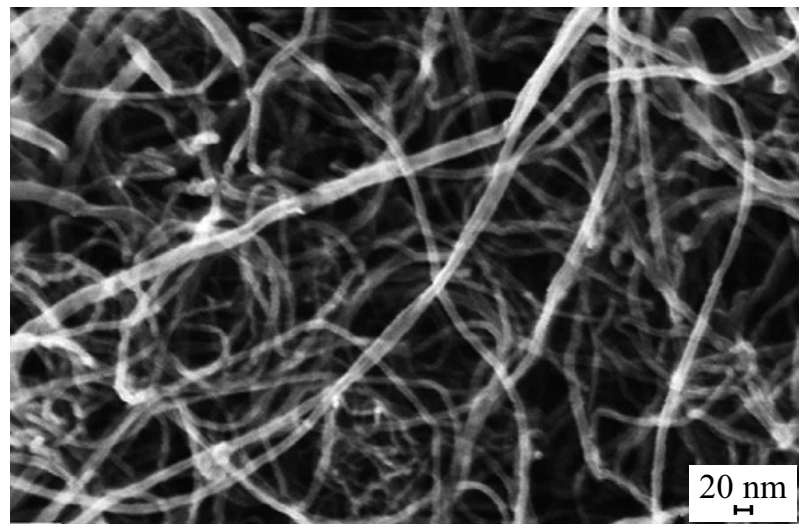

Рис. 2. РЭМ изображение многостенных УНТ типа Таунит Мд.

Таблица 2. Структурные характеристики (данные производителя [25]) и элементный состав [26] УНТ типа Таунит МД

\begin{tabular}{l|c|c|c}
\hline \multicolumn{1}{c|}{ Параметр } & Значение & Элемент & $\begin{array}{c}\text { Содержа- } \\
\text { ние, mass. \% }\end{array}$ \\
\hline Внешний диаметр, $\mathrm{nm}$ & $8-30$ & $\mathrm{C}$ & 96.1 \\
Внутренний диаметр, $\mathrm{nm}$ & $5-15$ & $\mathrm{O}$ & 3.86 \\
Длина, $\mu \mathrm{m}$ & $\geq 20$ & - & - \\
Насыпная плотность, & $0.025-0.06$ & - & - \\
g/cm & & & - \\
Удельная поверхность, & $\geq 270$ & - & - \\
$\mathrm{m}^{2} / \mathrm{g}$ & & &
\end{tabular}

от примесей катализаторов, используемых при их получении посредством кислотной обработки, промывки дистиллированной водой и сушки. В качестве кислоты использовали азотную кислоту, разбавленную водой в объемном отношении 1:1. Обработку вели при температуре около $100^{\circ} \mathrm{C}$ в течение $\sim 15 \mathrm{~min}$. Была выбрана азотная кислота, так как она наиболее полно растворяет примеси (установлено опытным путем). Характеристики используемых УНТ представлены в табл. 2. Наличие в материале значительного количества кислорода связано с его присоединением в процессе кислотной обработки в окислительной среде.

\subsection{5. Графеноподобный материал на основе терморасширенного графита}

Терморасширенный графит (ТРГ) использовали в форме порошка, структура которого показана на рис. 3. В качестве ТРГ использовали углеродный материал [27]. Как видно из рисунка, материал имеет структуру сросшихся пластин. Исходный материал аттестовали по структурным характеристикам и элементному составу. Данные исследования исходного ТРГ методами адсорбционной спектроскопии (низкотемпературная адсорбция азота) и 


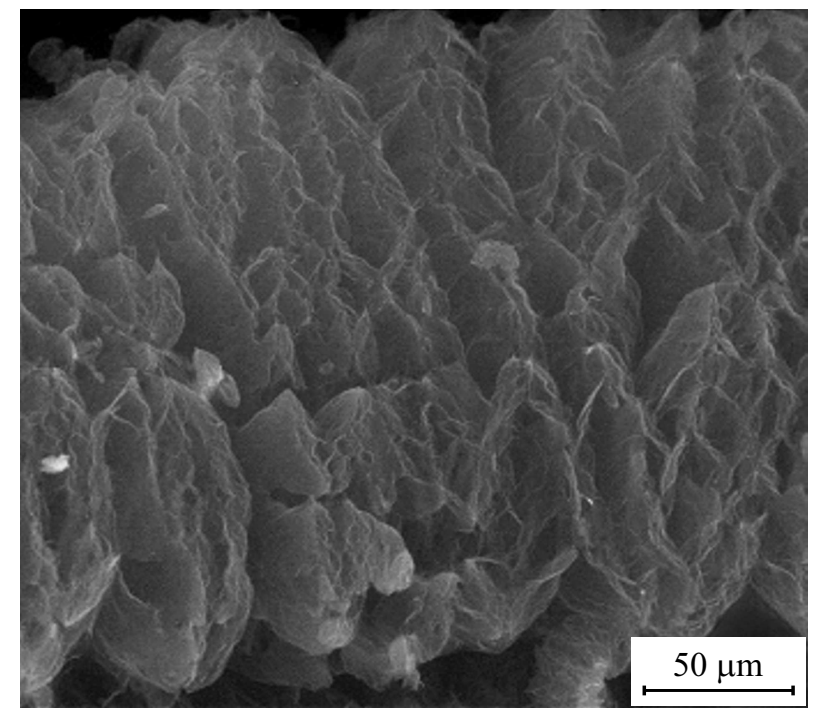

Рис. 3. Микрофотография исходного порошка терморасширенного графита.

Таблица 3. Структурные характеристики и элементный состав ТРГ

\begin{tabular}{l|c|c|c}
\hline \multicolumn{1}{c|}{ Параметр } & Значение & Элемент & $\begin{array}{c}\text { Содержание, } \\
\text { таss. \% }\end{array}$ \\
\hline $\begin{array}{l}\text { Насыпная } \\
\text { плотность, } \mathrm{g} / \mathrm{cm}^{3}\end{array}$ & 0.002 & $\mathrm{C}$ & $91.1-92.8$ \\
\hline $\begin{array}{l}\text { Удельная площадь } \\
\text { поверхности (по } \\
\text { БЭТ), } \mathrm{m}^{2} / \mathrm{g}\end{array}$ & 143 & $\mathrm{I}$ & $2.62-3.18$ \\
\hline- & - & $\mathrm{O}$ & $3.01-1.81$ \\
\multicolumn{1}{c}{} & - & $\mathrm{Br}$ & $0.23-0.48$
\end{tabular}

рентгеновской электронной спектроскопией приведены в табл. 3.

Исходя из типа изотермы адсорбции азота (II тип) и типа петли гистерезиса (Н3) материал имеет щелевидные поры, ограниченные плоскопараллельными структурными элементами. Наличие примесей галогенов и кислорода связано с технологией ТРГ. Интервал содержаний того или иного элемента связан с анализом различных областей поверхности образца.

В процессе приготовления электродного материала (включает ультразвуковую обработку, см. ниже), как и в процессе электрохимического воздействия происходило расщепление ТРГ на пластины [28].

\subsection{6. Протонпроводящий полимер типа Nafion}

Для введения иономера в электродный материал использовали коммерческий продукт Ion Power Inc. DUPONT DE2020 — водно-пропанольный раствор Nafion концентрации $20 \%$.

\section{2. Образцы. Приготовление дисперсии}

Для исследования изготавливали образцы на ДВЭ. Исходным электродным материалом для этих образцов служили дисперсии твердых компонентов в водно-спиртовой среде соответствующего компонентного состава.

Технологические операции приготовления дисперсии электродного материала для ДВЭ включали две стадии: механическое и ультразвуковое диспергирование смеси точных навесок компонентов в смеси и-пропанол-вода. Объемное соотношение жидких составляющих и-пропанол:вода находилось в диапазоне $1: 1-1: 5$. Отношение твердой фазы к жидкой (т:ж) в конечной дисперсии при этом находилось в диапазоне 1:40-1:80. Формирование части электродов проводили способом, предусматривающим предварительное коагулирование Nafion из его раствора в жидкой фазе с последующим введением в структуру электрода $[26,29]$. Для этого коммерческий раствор Nafion в заданной концентрации перед добавлением в дисперсию разбавляли водой в объемном отношении $1: 1$.

Механическое диспергирование выполняли на магнитной мешалке типа Milaform MM-5M со скоростью вращения якоря $\sim 400$ оборотов в минуту с изолированным в пластиковый кожух якорем до визуально однородной (без видимых комочков) массы $\sim 0.5 \mathrm{~h}$. Последующее ультразвуковое диспергирование проводили в ультразвуковой ванне типа Branson 3510 в течение $(40-100) \mathrm{h}$ до получения однородной, не расслаивающейся в течение $1 \mathrm{~min}$ дисперсии.

\section{3. Дисковый вращающийся электрод}

Образцы для исследования на ДВЭ готовили путем нанесения дисперсии компонентов электродного материала на стеклоуглеродную поверхность ДВЭ.

Перед нанесением дисперсии поверхность электрода отполировывали пастой ГОИ, промывали дистиллированной водой и изопропанолом. Снимали тестовую циклическую вольтамперограмму для оценки холостых токов. После нанесения капли дисперсии электрод высушивали под вытяжкой на воздухе при комнатной температуре. После этого часть материала, выходящую за пределы стеклоуглеродной поверхности, стирали.

По оценкам загрузка электродного материала находилась в пределах $0.2-2 \mathrm{mg} / \mathrm{cm}^{2}$ для разных образцов.

\section{4. ДВЭ. Проведение измерений}

Измерения проводили в трехэлектродной электрохимической ячейке в растворе $0.5 \mathrm{M}$ серной кислоты, находящейся в равновесии с воздухом при комнатной температуре $\left(\sim 23^{\circ} \mathrm{C}\right)$. В качестве электрода сравнения использовали хлорсеребряный электрод, в качестве вспомогательного электрода использовали электрод из спектрально-чистого графита. Вращение электрода осуществляли на установке типа ВЭД-06, совмещенной 
с потенциостатом типа IPC Pro. Экспериментальные данные регистрировали на управляющем персональном компьютере в программе IPC-Pro MF 8.70.

Материал наносили на электроды, представляющие собой стеклоуглеродные диски диаметром $3 \mathrm{~mm}$, запрессованные в тефлоновый кожух ( $7 \mathrm{~mm}$ в диаметре).

Перед проведением измерений образец электрохимически очищали путем циклического изменения электродного потенциала в диапазоне от -0.15 до $0.8 \mathrm{~V}$ со скоростью $50 \mathrm{mV} / \mathrm{s}$. При этом регистрировали циклические вольтамперограммы (ЦВА). Очистку проводили до прекращения изменения ЦВА (обычно около 40 циклов). Вольтамперограммы регистрировали при различных скоростях вращения ДВЭ в двух направлениях изменения потенциала, от -0.1 до $0.8 \mathrm{~V}$ и обратно, со скоростью $1 \mathrm{mV} / \mathrm{s}$. Экспериментальное значение силы тока вычисляли как среднее прямого и обратного хода. Электрическое сопротивление измерительной цепи $\mathrm{R}$ измеряли методом прерывания тока [30]. Фоновые токи рабочего электрода регистрировали в рабочем диапазоне потенциалов при нулевой скорости вращения в статическом режиме. Стабилизация тока происходила в течение $\leq 1 \mathrm{~min}$.

\section{3. Вычисления}

\section{1. Вычисление пористости}

Толщину электродов измеряли толщиномером с разрешением $0.5 \mu \mathrm{m}$ в 10 точках слоя. За результирующее значение толщины принимали среднее арифметическое. Площадь электродов составляла $1 \mathrm{~cm}^{2}$. Пористость электродов вычисляли, исходя из известного компонентного состава, толщины и площади по соотношению

$$
P=1-\frac{\sum_{i=1}^{n}\left(\left(\omega_{i} \cdot G\right) / d_{i}\right)}{V},
$$

где $P$ - пористость (объемная доля пор) электрода; $V$ - объем электрода (в данном случае при длине и ширине электрода по $1 \mathrm{~cm}$, объем численно равен толщине); $\omega_{i}$ - массовая доля $i$-го компонента; $G-$ масса электрода; $d_{i}$ - плотность $i$-го компонента.

\section{2. Вычисление электрохимически активной площади поверхности платины}

После очистки регистрировали три цикла ЦВА для измерения электрохимически активной площади поверхности платины. Эту величину измеряли в водородной области ЦВА по десорбции водорода [31]. Для этого путем численного интегрирования вычисляли заряд, пошедший на десорбцию водорода. Интегрировали область, ограниченную сверху ЦВА-кривой и снизу - горизонтальной линией, соответствующей току заряжения двойного электрического слоя (для исключения заряда, пошедшего на заряжение двойного электрического слоя -
ДЭС). Полученный заряд, пошедший на десорбцию водорода, делили на коэффициент, соответствующий заряду водорода, десорбированному с единицы площади поверхности платины $\left(210 \mu \mathrm{C} / \mathrm{cm}^{2}\right)$ в соответствии с соотношением

$$
S_{\mathrm{Pt}}=\left(\int_{E_{1}}^{E_{2}} I \cdot d E\right) / 210 .
$$

С целью выяснения влияния скорости поляризации на результаты измерения площади поверхности платины проводили измерения при различных скоростях поляризации в диапазоне $10-1000 \mathrm{mV} / \mathrm{s}$. При скорости от 30 до $100 \mathrm{mV} / \mathrm{s}$ измеряемая площадь поверхности имела постоянное значение в пределах $10 \%$ для толщины слоя до $\sim 40 \mu \mathrm{m}$.

\section{3. Вычисление электрохимически активной суммарной площади пористого электрода}

Использовали известное положение: поляризационная емкость $C_{P}=16-20 \mu \mathrm{F} / \mathrm{cm}^{2}[32]$. В соответствии с этим площадь $S$ вычисляли, исходя из скорости поляризации $v$ и тока заряжения ДЭС $-I$, по соотношению

$$
S=I /\left(v \cdot C_{P}\right)
$$

\section{4. Коррекция электродного потенциала}

Для коррекции потенциала использовали электрическое сопротивление измерительной цепи $R$ (см. выше). По полученным данным делали поправку (вычисляли $E_{\text {correction }}$ - потенциал с учетом поправки) $E$ для каждого текущего значения тока $I$ для экспериментальных полярограмм по соотношению

$$
E_{\text {correction }}=E+I \cdot R \text {. }
$$

\section{5. Вычисление предельных плотностей тока}

По полярограммам, снятым при различных скоростях вращения ДВЭ, находили значения предельного тока для каждой скорости вращения ДВЭ. На основе этих значений строили кинетические кривые в координатах Левича: $1 / I\left(1 / \omega^{1 / 2}\right)$. Полученные точки аппроксимировали прямыми. Экстраполировали полученные прямые на ось обратных токов, соответствующую бесконечной скорости вращения ДВЭ, и находили величину внутридиффузионного тока по отсечке.

\section{4. Полученные результаты}

Для непокрытого катализатором дискового электрода снимали ЦВА. Полученные токи не превышали величину $\sim 5 \mu \mathrm{A}$ по абсолютной величине. Это обеспечивает практическое отсутствие влияния поверхности электрода на результаты измерения нанесенного образца. На 
рис. 4 приведены результаты измерения фонового тока в статическом режиме для образца (Pt/C $+10 \%$ Nafion). Как видно из рис. $4, a$, фоновый ток выходит на практически стационарное значение за $1 \mathrm{~min}$. Рис. $4, b$ демонстрирует результирующую стационарную полярограмму, представляющую фоновый ток. Величина фонового тока в водородной области (область измерения площади электрохимически активной поверхности платины) составила $0.012 \mathrm{~mA}$, тогда как ток адсорбции/десорбции водорода составляет $\sim 0.5 \mathrm{~mA}$. Таким образом, влияние фонового тока на измерение площади платины несущественно.

На рис. 5 приведены характерные вольтамперограммы при разных скоростях врашения ДВЭ для образца (34\%УНТ Таунит МД+Pt/C+32\%Nafion). Вольтамперограммы регистрировали в двух направлениях изменения электродного потенциала. Пунктирными линиями показаны расчетные (теоретические) предельные плотности внешнедиффузионных токов. Из рис. 5 видно, что плотности токов прямого и обратного хода изменения потенциала несколько различаются, образуя некий гистерезис. Это связано с хорошо известной нестационарностью процесса при динамическом режиме измерений (скорость поляризации $1 \mathrm{mV} / \mathrm{s}$ ). Из рис. 5 видно, что измеряемые плотности предельных токов (участки полярограмм, параллельные оси потенциалов в
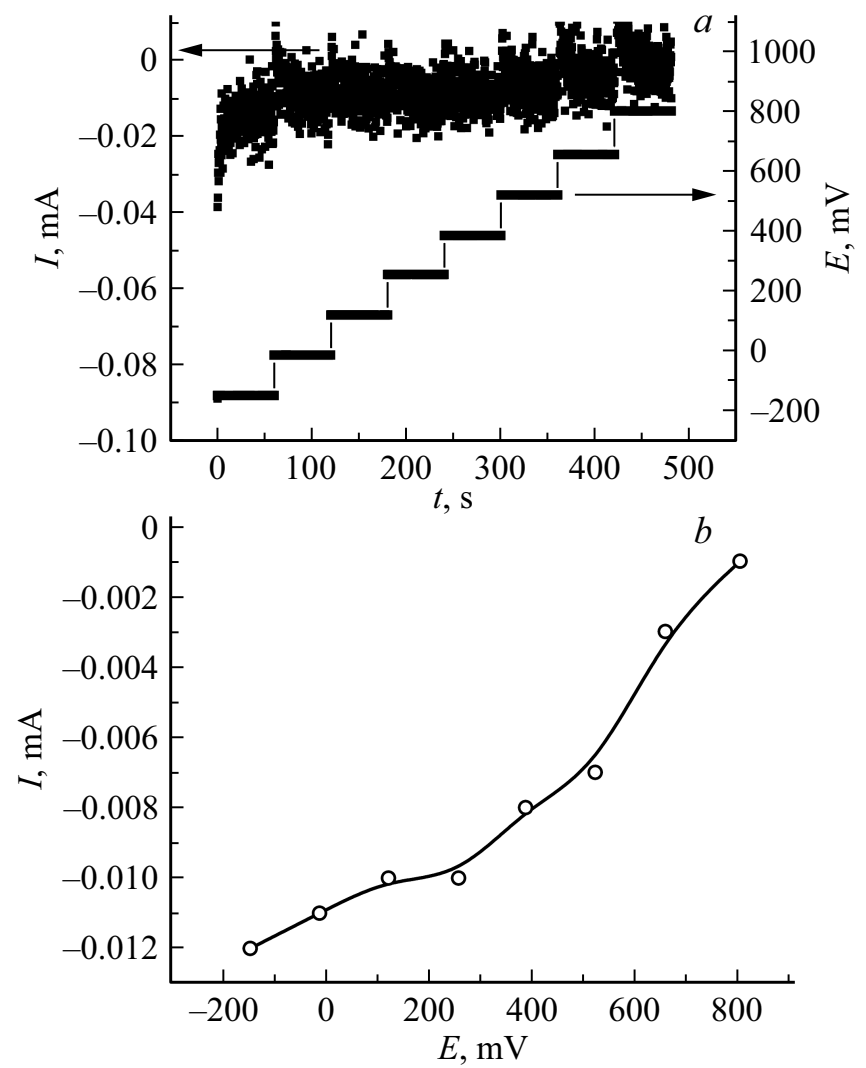

Рис. 4. Фоновый ток образца (Pt/C+10\%Nafion) на ДВЭ: $a-$ ступенчатое изменение электродного потенциала и динамика установления фонового тока; $b-$ стационарные значения фонового тока при различных электродных потенциалах.

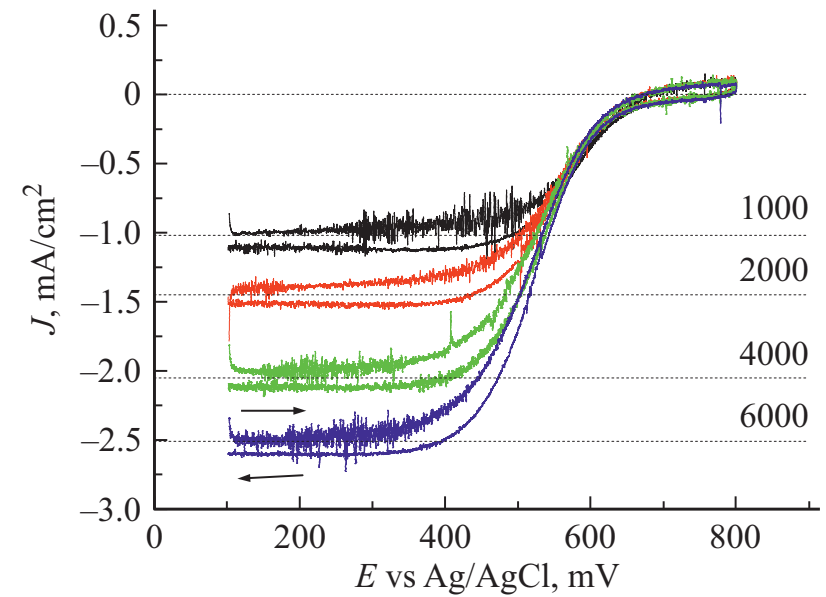

Рис. 5. Вольтамперограммы образца (34\%УНТ Таунит $\mathrm{MД}+\mathrm{Pt} / \mathrm{C}+32 \%$ Nafion) на дисковом вращающемся электроде при разной скорости вращения. Стрелками указано направление развертки потенциала.

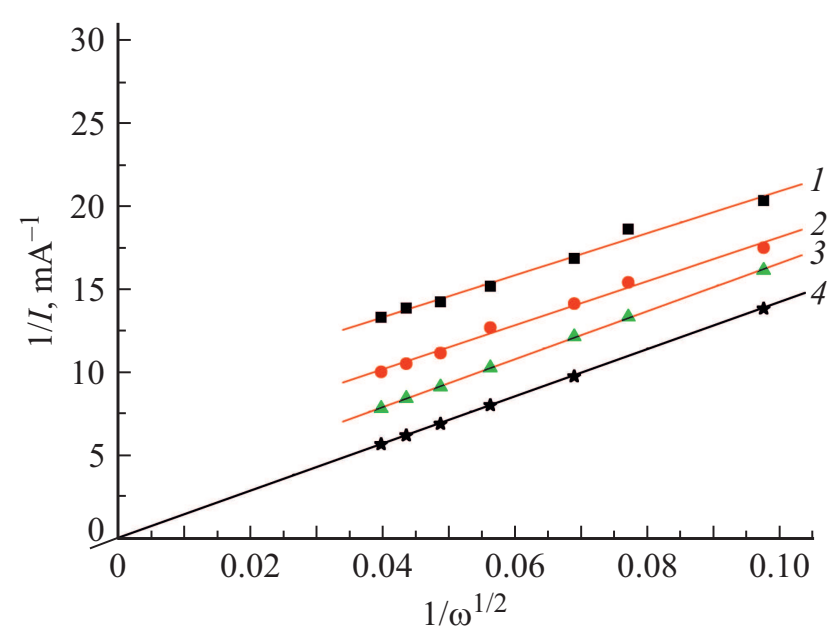

Рис. 6. Кинетические кривые электродного материала $\mathrm{Pt} / \mathrm{C}-\mathrm{Nafion}, 1-(\mathrm{Pt} / \mathrm{C}+80 \%$ Nafion $) ; 2-(\mathrm{Pt} / \mathrm{C}+60 \%$ Nafion $)$; $3-(\mathrm{Pt} / \mathrm{C}+10 \%$ Nafion $) ; 4-$ расчетная предельная плотность внешнедиффузионного тока.

интервале $-150-+400 \mathrm{mV}$ ) практически соответствуют теоретическим внешнедиффузионным, т.е. процесс ограничен внешней диффузией и внутреннее диффузионное сопротивление электрода пренебрежимо мало.

На рис. 6 и 7 приведены кинетические кривые, построенные на основании полярограмм, аналогичных рис. 5 , для материалов различных систем и составов. Точки на кинетических кривых соответствуют экспериментальным предельным плотностям тока для соответствующей скорости вращения электрода. Отсечки по оси ординат, полученные при линейной экстраполяции прямых на область бесконечных скоростей вращения ДВЭ, использованы для вычисления плотности внутридиффузионного тока (табл. 4,5). 

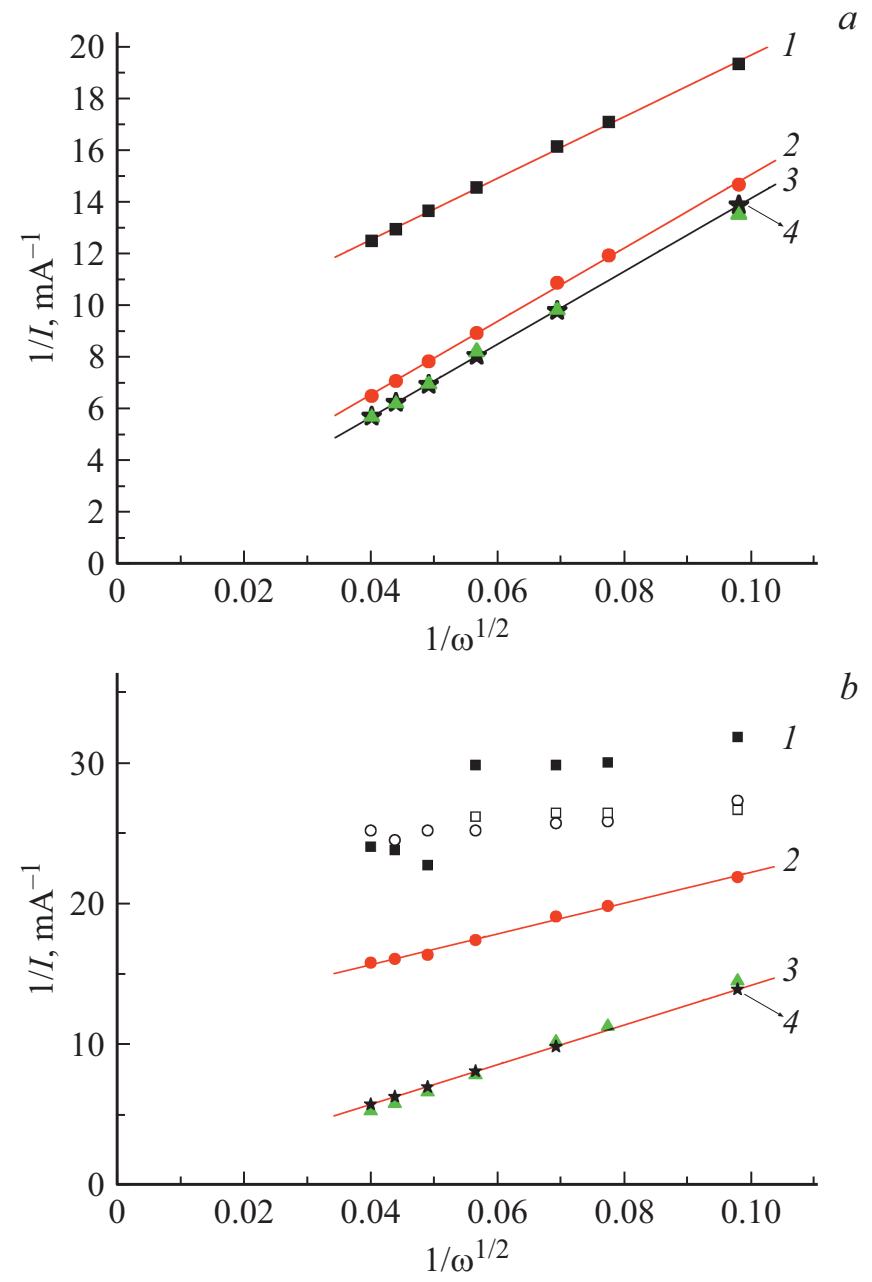

Рис. 7. Кинетические кривые электродного материала: $a-$ УНТ Таунит МД $+\mathrm{Pt} / \mathrm{C}+$ Nafion;

$1-(10 \%$ УНТ Таунит МД $+\mathrm{Pt} / \mathrm{C}+80 \%$ Nafion $)$;

$2-(20 \%$ УНТ Таунит МД $+\mathrm{Pt} / \mathrm{C}+60 \%$ Nafion $)$;

$3-(34 \%$ УНТ Таунит МД $+\mathrm{Pt} / \mathrm{C}+32 \%$ Nafion $)$;

4 - расчетная предельная плотность внешнедиффузионного тока; $b-\mathrm{TP} \Gamma+\mathrm{Pt} / \mathrm{C}+$ Nafion;

$1-(10 \% \mathrm{TP} \Gamma+\mathrm{Pt} / \mathrm{C}+80 \%$ Nafion $)$;

$2-(20 \% \mathrm{TP} \Gamma+\mathrm{Pt} / \mathrm{C}+60 \%$ Nafion $)$;

$3-(45 \% \mathrm{TP} \Gamma+\mathrm{Pt} / \mathrm{C}+18 \%$ Nafion $)$;

4 - расчетная предельная плотность внешнедиффузионного тока.

Для образцов с ТРГ (рис. 7,b) при больших содержаниях Nafion (точки под № 1) точки располагаются практически параллельно оси абсцисс. То есть плотность тока не зависит от скорости вращения ДВЭ. Вольтамперограммы не имеют выраженного насыщения по току (участка, параллельного оси потенциалов), что свидетельствует о недостаточном количестве платины и протекании процесса в области смешанной кинетики (диффузионные и реакционные токи близки по величине).

В табл. 4 представлены экспериментальные данные о предельных внутридиффузионных токах, измеренных на
ДВЭ для различных электродных материалов. В колонке с площадью платины приведены результаты измерения электрохимически активной площади поверхности платины на электроде: два значения через тире, соответствующие площади перед началом и по окончании измерений. Для образца $(10 \% \mathrm{TP \Gamma}+\mathrm{Pt} / \mathrm{C}+80 \% \mathrm{Nafion})$ вольтамперограммы не имели насыщения тока, характерного для диффузионного контроля в области больших поляризаций. При этом зависимость тока от скорости вращения электрода в координатах Левича практически не имеет наклона (рис. $7, b$ ), следовательно, процесс ограничен не диффузией, а реакцией переноса заряда. Это может быть связано с малой концентрацией платины в электроде $(4 \%)$.

В табл. 5 приведены данные о плотностях тока для образца $(20 \%$ УНТ Таунит МД+Pt/C $+60 \%$ Nafion $)$, полученные для электродов с различным количеством электродного материала.

Анализируя экспериментальные данные табл. 4 и 5, можно сделать вывод о наличии следующих закономерностей:

1. В рамках одной группы составов наблюдается корреляция между пористостью и плотностью диффузионного тока.

2. Для различных групп материалов наибольшие значения предельной плотности тока при прочих равных условиях наблюдаются для композита, содержащего длинные УНТ; образцы с ТРГ демонстрируют весьма резкое уменьшение пористости с увеличением содержания Nafion и уменьшение предельной плотности тока.

3. В широких (около одного порядка) пределах загрузки платины и соответственно толщины электрода плотность предельного тока практически постоянна, что соответствует представлениям о вытеснении фронта реакции при больших поляризациях на поверхность электрода.

С точки зрения диффузионного сопротивления, важным фактором является соотношение концентраций иономера (Nafion) и платины, поскольку, как отмечено выше, Nafion создает ряд барьеров по пути реакционного газа к поверхности платины. Обычно используют критерий, представляющий собой отношение массовых содержаний иономера (Nafion) и платины: Nafion/Pt (табл. 4).

Как видно из табл. 4, общей тенденцией является уменьшение диффузионного тока с увеличением Nafion/Pt. Однако эти зависимости для электродов с разными добавками различаются. Так, для электродов без добавок наблюдаются самые низкие плотности тока, тогда как в случае добавки УНТ Таунит МД плотности тока наибольшие. Значение плотности тока для электродов с „короткими“ УНТ имеет промежуточное значение. На рис. 8 для наглядности показаны эти зависимости в графическом виде. По оси ординат отложены обратные величины тока, следовательно, нулевое значение соответствует практически незаметному диффузионному сопротивлению. 
Таблица 4. Пористость, плотности предельного тока, измеренные на дисковом вращающемся электроде, массовое отношение иономер (Nafion)/платина (Nafion/Pt) для электродных материалов разного состава при условиях: раствор $0.5 \mathrm{M}$ серной кислоты в равновесии с воздухом, $t=23^{\circ} \mathrm{C}$, атмосферное давление

\begin{tabular}{|c|c|c|c|c|c|c|c|}
\hline \multirow[b]{2}{*}{ Образец } & \multicolumn{3}{|c|}{ Состав, \% } & \multirow{2}{*}{$\begin{array}{c}S_{\mathrm{Pt}} \text { на } \\
\text { ДВЭ, } \\
\mathrm{cm}^{2}\end{array}$} & \multirow[b]{2}{*}{ Пористость, \% } & \multirow{2}{*}{$\begin{array}{c}I d i f f \\
\text { (на электрод), } \\
\text { mА } \\
\text { (коэффициент } \\
\text { корреляции } R \text { ) }\end{array}$} & \multirow[b]{2}{*}{ Nafion/Pt } \\
\hline & $\mathrm{Pt}$ & Nafion & Добавка & & & & \\
\hline \multicolumn{8}{|c|}{ без добавок } \\
\hline $\mathrm{Pt} / \mathrm{C}+10 \%$ Nafion & 36 & 10 & - & $2.54-1.66$ & 62 & $\begin{array}{c}0.466 \\
(R=0.99985)\end{array}$ & 0.28 \\
\hline $\mathrm{Pt} / \mathrm{C}+60 \%$ Nafion & 16 & 60 & - & $2.95-2.23$ & 44 & $\begin{array}{c}0.204 \\
(R=0.99565)\end{array}$ & 3.7 \\
\hline $\mathrm{Pt} / \mathrm{C}+80 \%$ Nafion & 8 & 80 & - & $2.56-0.8$ & 39 & $\begin{array}{c}0.121 \\
(R=0.99356)\end{array}$ & 10 \\
\hline \multicolumn{8}{|c|}{ с УНТ Плазмас („короткие“ УНТ) } \\
\hline $\begin{array}{l}46 \% \text { УНТ } \\
\text { Плазмас }+\mathrm{Pt} / \mathrm{C}+8 \% \text { Nafion }\end{array}$ & 9 & 8 & 46 & $3.34-2.78$ & 74 & $\begin{array}{c}0.542 \\
(R=0.99944)\end{array}$ & 0.91 \\
\hline \multicolumn{8}{|c|}{ с УНТ Таунит МД (длинные“ УНТ) } \\
\hline $\begin{array}{l}34 \% \text { УНТ Таунит } \\
\mathrm{MД}+\mathrm{Pt} / \mathrm{C}+32 \% \text { Nafion }\end{array}$ & 14 & 32 & 34 & $3.56-2.39$ & 74 & $\begin{array}{c}1 / I \approx 0 \\
(R=0.99919)\end{array}$ & 2.3 \\
\hline $\begin{array}{l}20 \% \text { УНТ Таунит } \\
\text { МД+Pt/C+60\%Nafion }\end{array}$ & 8 & 60 & 20 & $2.78-2.69$ & 56 & $\begin{array}{c}1.11 \\
(R=0.99954)\end{array}$ & 7.7 \\
\hline $\begin{array}{l}10 \% \text { УНТ Таунит } \\
\text { МД+Pt/C+80\%Nafion }\end{array}$ & 4 & 80 & 10 & $2.51-1.64$ & 19 & $\begin{array}{c}0.128 \\
(R=0.99946)\end{array}$ & 20 \\
\hline \multicolumn{8}{|c|}{ с терморасширенным графитом } \\
\hline $45 \% \mathrm{TP} \Gamma+\mathrm{Pt} / \mathrm{C}+18 \%$ Nafion & 18 & 10 & 45 & $0.44-0.53$ & 62 & $\begin{array}{c}1 / I \approx 0 \\
(R=0.99951)\end{array}$ & 0.56 \\
\hline $20 \% \mathrm{TP} \Gamma+\mathrm{Pt} / \mathrm{C}+60 \%$ Nafion & 8 & 60 & 20 & $3.60-3.10$ & 10 & $\begin{array}{c}0.1 \\
(R=0.99725)\end{array}$ & 7.7 \\
\hline $10 \% \mathrm{TP} \Gamma+\mathrm{Pt} / \mathrm{C}+80 \%$ Nafion & 4 & 80 & 10 & $2.46-1.87$ & $\sim 0$ & $\begin{array}{c}\text { нет насыщения } \\
\text { по току на } \\
\text { полярограмме }\end{array}$ & - \\
\hline
\end{tabular}

Отметим, что в случае измерений диффузионной плотности тока на ДВЭ исключается влияние ионного сопротивления и размера пор электрода. Это происходит в силу двух причин:

1. В эксперименте происходит пропитывание электрода раствором электролита, что приводит к выравниванию ионного сопротивления электродов независимо от доли Nafion;

2. Длина свободного пробега молекул в жидкости (в растворе электролита), как известно, существенно меньше, чем в газе, поэтому диффузия ограничена межмолекулярными столкновениями, а не стенками пор.

Из этого следует, что определяющим параметром в данном случае становится толщина пленки Nafion, покрывающей поверхность платины.
Из рис. $8, a$ видно, что для всех образцов увеличение критерия Nafion/Pt приводит к возрастанию диффузионного сопротивления (уменьшению диффузионного тока). Это ожидаемый результат, так как при увеличении доли Nafion увеличивается толщина его структурных элементов, которую необходимо пройти молекулам кислорода. При этом интересно отметить, что для систем с различными добавками кривые лежат в областях различных значений диффузионной плотности тока. Наименьшее сопротивление у образцов с УНТ Таунит МД, т.е. при одинаковом отношении Nafion/Pt для образцов, содержащих УНТ Таунит МД, диффузионное сопротивление существенно меньше, чем для других систем.

Аналогичная картина наблюдается на зависимостях диффузионного тока от пористости (рис. $8, b$ ): для всех 
образцов чем больше пористость, тем больше диффузионной ток. Однако кривые расположены ближе друг к другу, чем на зависимостях Nafion/Pt (рис. 8,a). При этом при равной пористости величины диффузионного тока для образцов с УНТ Таунит МД также выше, чем для электродов другого состава.

Эти факты можно объяснить различной структурной организацией электродов с разными добавками [26,33,34]. В случае добавки УНТ Таунит МД, Nafion пространственно несколько рассогласован с платиной и при том же отношении Nafion/Pt и пористости, что и в других образцах, создает меньшее диффузионное сопротивление кислороду. Отметим, что „короткие“ УНТ Плазмас (табл. 4) несколько уменьшают диффузионное сопротивление электрода, вероятно, в силу тех же причин, что и длинные УНТ, однако их влияние на пространственное рассогласование структурных элементов электрода менее выражено из-за меньшей длины.

Согласно [34], структура композита сильно зависит от используемой добавки. При формировании электродного материала Nafion структурируется в двух формах: в
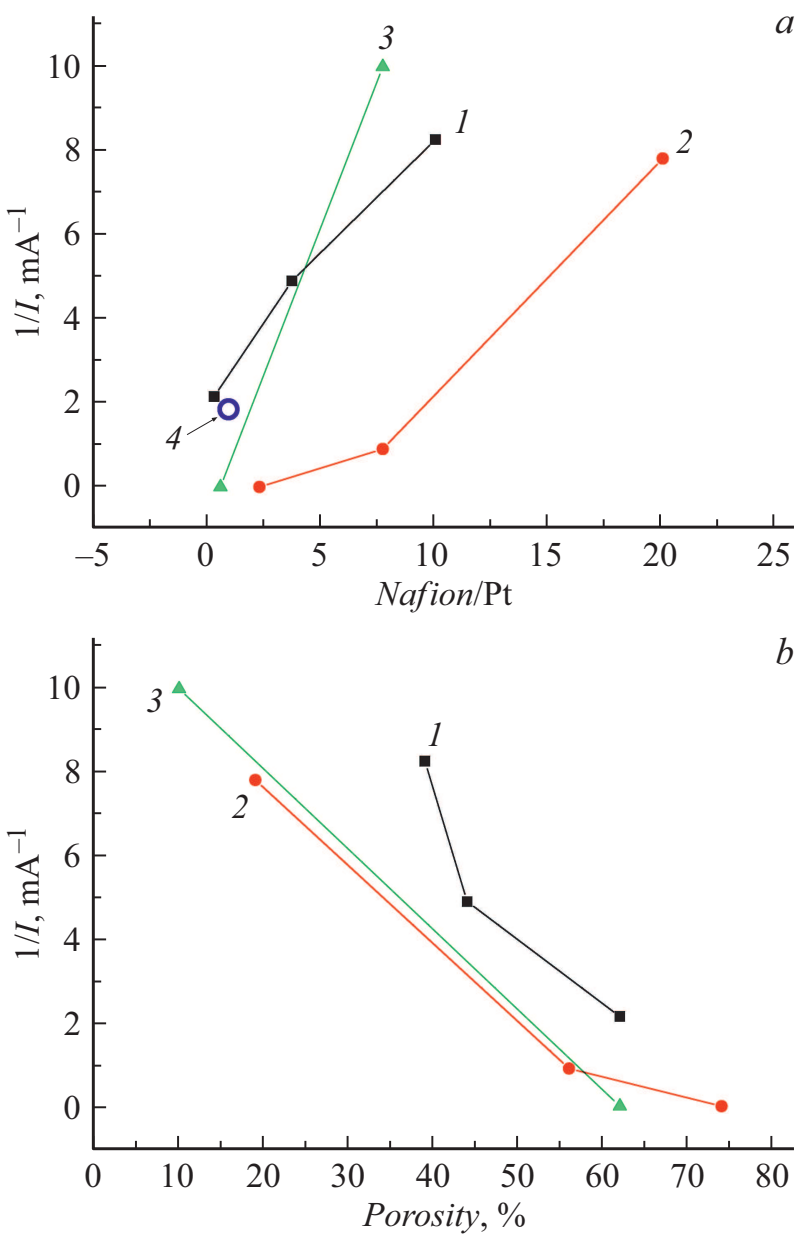

Рис. 8. Зависимости обратной силы диффузионного тока от отношения долей Nafion/ $\mathrm{Pt}$ в электроде $(a)$ и от пористости $(b)$ для электродов с различными добавками; 1 - образцы без добавок; $2-$ с УНТ Таунит МД; $3-$ с ТРГ; $4-$ с УНТ Плазмас.
Таблица 5. Предельные плотности тока, измеренные на ДВЭ, для различных количеств материала, нанесенного на ДВЭ: раствор $0.5 \mathrm{M}$ серной кислоты в равновесии с воздухом, $t=23^{\circ} \mathrm{C}$, атмосферное давление; образец (20\%УНТ Таунит $\mathrm{MД}+\mathrm{Pt} / \mathrm{C}+60 \%$ Nafion $)$

\begin{tabular}{l|c|c}
\hline $\begin{array}{c}\text { Количество } \\
\text { материала на ДВЭ }\end{array}$ & $S_{\mathrm{Pt}}$ на ДВЭ, $\mathrm{cm}^{2}$ & $\begin{array}{c}\text { Idiff } \\
\text { (на электрод), } \mathrm{mA}\end{array}$ \\
\hline 1 капля & $0.86-0.82$ & 0.905 \\
4 капли & $2.78-2.69$ & 1.11 \\
7 капель & $7.72-6.69$ & 1.00
\end{tabular}

форме кластеров и в форме пленки на поверхности углеродных материалов. Длинные УНТ и ТРГ образуют каркасную структуру за счет длинных структурных элементов, контактирующих между собой. Это обеспечивает транспорт электронов и протонов в широком диапазоне составов. В случае материала с длинными УНТ платина располагается в форме отдельных островков внутри пористого каркаса УНТ. В случае материала с ТРГ платина равномерно распределяется в материале, а Nafion в основном структурно связан с пластинами ТРГ.

Из сказанного следует, что в материалах, содержащих УНТ (Таунит МД, Плазмас) и ТРГ, Nafion присутствует в форме пространственно изолированных кластеров и покрывает поверхность добавки, что способствует большей доступности поверхности платины для молекул кислорода по сравнению с платинированной углеродной сажей Vulcan. Экспериментальные данные по измерению диффузионного тока подтверждают это.

\section{Выводы}

Проведенные исследования показали, что композит, содержащий длинные УНТ, обладает самым интенсивным массопереносом и наиболее перспективен для технического использования. Увеличение отношения Nafion/Pt приводит к увеличению сопротивления переносу кислорода для всех систем, однако наименее чувствительны к этому электроды с длинными УНТ, наиболее чувствительны структуры с ТРГ. Сильный эффект от длинных УНТ связан с наиболее выраженным в этом случае пространственным рассогласованием компонентов электродной структуры (наночастицы платины, Nafion, поры).

\section{Благодарности}

Электронно-микроскопические исследования выполнены с использованием оборудования федерального ЦКП „Материаловедение и диагностика в передовых технологиях“, поддержанного Минобрнауки России. 


\section{Конфликт интересов}

Авторы заявляют, что у них нет конфликта интересов.

\section{Список литературы}

[1] F.B. Spingler, A. Phillips, T. Schuler, M.C. Tucker, A.Z. Weber. Int. J. Hydrog. Energy, 42 (19), 13960 (2017). DOI: $10.1016 /$ j.jihydene.2017.01.036

[2] P. Kanninen, M. Borghei, V. Ruiz, E.I. Kauppinen, T. Kallio. Int. J. Hydrog. Energy, 37 (24), 19082 (2012). DOI: $10.1016 / /$ j.ijhydene.2012.09.138

[3] J.C. Calderón, N. Mahata, M.F.R. Pereira, J.L. Figueiredo, V.R. Fernandes, C.M. Rangel, L. Calvillo, M.J. Lázaro, E. Pastor. Int. J. Hydrog. Energy, 37 (8), 7200 (2012). DOI: 10.1016/j.ijhydene.2011.12.029

[4] F.A. Viva, M.M. Bruno, E.A. Franceschini, Y.R.J. Thomas, G.R. Sanchez, O. Solorza-Feria, H.R. Corti. Int. J. Hydrog. Energy, 39(16), 8821 (2014). DOI: 10.1016/j.ijhydene.2013.12.027 [T. Nagai, C. Jahn, H.Jia. J. Electrochem. Soc., 166 (7), F3111 (2019). DOI: $10.1149 / 2.0161907$ jes

[6] O.V. Korchagin, N.M. Zagudaeva, M.V. Radina, V.A. Bogdanovskaya, M.R. Tarasevich. Russ. J. Electrochem, 53 (6), 615 (2017). DOI: 10.1134/S1023193517060118

[7] P. Boillat, P. Oberholzer, A. Kaestner, R. Siegrist, E.H. Lehmann, G.G. Scherer, A. Wokau. J. Electrochem. Soc., 159, F210 (2012). DOI: 10.1149/2.017207jes

[8] J. Biesdorf, A. Forner-Cuenca, T.J. Schmidt, P. Boillat. J. Electrochem. Soc., 162 (10), F1243 (2015). DOI: $10.1149 / 2.0861510$ jes

[9] A. Forner-Cuenca, J. Biesdorf, V. Manzi-Orezzoli, L. Gubler, T.J. Schmidt, P. Boillat. J. Electrochem. Soc., 163 (13), F1389 (2016). DOI: $10.1149 / 2.0891613$ jes

[10] U. Beuscher. J. Electrochem. Soc., 153 (9), A1788 (2006). DOI: $10.1149 / 1.2218760$

[11] D.R. Baker, D.A. Caulk, K.C. Neyerlin, M.W. Murphy. J. Electrochem. Soc., 156 (9), B991 (2009). DOI: $10.1149 / 1.3152226$

[12] T. Hayashi, Y. Tabe, T. Chikahisa. ECS Trans, 75 (14), 373 (2016). DOI: $10.1149 / 07514.0373$ ecst

[13] Н.В. Глебова, А.О. Краснова, А.А. Томасов, Н.К. Зеленина, А.А. Нечитайлов. ЖТФ, 87 (12), 1865 (2017). DOI: 10.1134/S106378421712009X [N.V. Glebova, A.O. Krasnova, A.A. Tomasov, N.K. Zelenina, A.A. Nechitailov. Tech. Phys., 62 (12), 1863 (2017). DOI: $10.1134 / \mathrm{S} 106378421712009 \mathrm{X}]$

[14] Ю.В. Плесков, В.Ю. Филиновский. Вращающийся дисковый электрод (Наука, М., 1972)

[15] Ю.В. Плесков, В.Ю. Филиновский. Итоги науки и техники, сер. Электрохимия, 11, 57 (1976).

[16] Кинетика сложных электрохимических реакций, под ред. В.Е. Казаринов. (Наука, М., 1981), 309 с.

[17] Электронный ресурс. Режим доступа: URL: https://www.fuelcellstore.com/spec-sheets/vulcan-xc72 -spec-sheet.pdf

[18] Н.В. Глебова, А.А. Нечитайлов. Журн. Перспективные материалы, спец. выпуск „Функциональные наноматериалы и высокочистые вещества“, 9, 71 (2010)
[19] M. Uchida, Y. Aoyama, M. Tanabe, N. Yanagihara, N. Eda, A. Ohta. J. Electrochem. Soc., 142, 2572 (1995). DOI: $10.1149 / 1.2050055$

[20] J. Mc Breen, H. Olender, S. Srinivasan, K. Kordesch. J. Appl. Electrochem., 11, 787 (1981). DOI: 10.1007/BF00615184

[21] D. Pantea, H. Darmstadt, S. Kaliaguine, L. Summchen, C. Roy. Carbon, 39, 1147 (2001). DOI: $10.1016 / \mathrm{S} 0008-6223(00) 00239-6$

[22] E. Antolini. Appl. Catalys. B: Environmental, 88, 1 (2009). DOI: $10.1016 /$ j.apcatb.2008.09.030

[23] A.K. Filippov, M.A. Fedorov. Abstract of 4-th International Conference on Electromagnetic Processing of Materials. EPM 2003 (Lyon, France, 2003), p. 131.

[24] R.A. Filippov, A.K. Filippov, A.B. Freidin. Saint-Petersburg International Workshop on NanoBiotechnologies (Saint-Petersburg, Russia, 2006), p. 74.

[25] Электронный ресурс. Режим доступа: URL. http://www.nanotc.ru/producrions/87-cnm-taunit

[26] А.О. Краснова, Н.В. Глебова, А.А. Нечитайлов. ЖПХ, 89 (6), 756 (2016). DOI: 10.1134/S1070427216060112 [A.O. Krasnova, N.V. Glebova, A.A. Nechitailov. Russ. J. Appl. Chem., 89 (6), 916 (2016). DOI: $10.1134 / \mathrm{S} 1070427216060112]$

[27] В.И. Мазин, Е.В. Мазин. Способ получения пористого углеродного материала на основе высокорасщепленного графита. Патент РФ № 2581382. Приоритет от 22.04.2014. Опубликовано 20.04.2016 в Бюл. № 11

[28] Н.В. Глебова, А.О. Краснова, А.А. Нечитайлов. ЖПХ, 91 (8), 1111 (2018). DOI: 10.1134/S1070427218080037 [N.V. Glebova, A.O. Krasnova, A.A. Nechitailov. Russ. J. Appl. Chem., 91 (8), 1262 (2018). DOI: $10.1134 / \mathrm{S} 1070427218080037]$

[29] S. Litster, G. McLean. J. Power Sources, 130, 61 (2004). DOI: $10.1016 /$ j.jpowsour.2003.12.055

[30] K.R. Cooper, M. Smith. J. Power Sources, 160, 1088 (2006). DOI: 10.1016/j.jpowsour.2006.02.086

[31] А.А. Нечитайлов, Н.В. Глебова. Электрохимия, 50, 835 (2014). DOI: 10.1134/S1023193514080102 [A.A. Nechitailov, N.V. Glebova. Russ. J. Electrochem., 50 (8), 751 (2014). DOI: $10.1134 / \mathrm{S} 1023193514080102]$

[32] F. Beck, M. Dolata, E. Grivei, N. Probst. J. Appl. Electrochem., 31, 845 (2001). DOI: 10.1023/A:1017529920916

[33] А.О. Краснова, Н.В. Глебова, Д.В. Жилина, А.А. Нечитайлов. ЖПХ, 90 (3), 299 (2017). DOI: $10.1134 / \mathrm{S} 1070427217030065$ [A.O. Krasnova, N.V. Glebova, D.V. Zhilina, A.A. Nechitailov. Russ. J. Appl. Chem., 90, 361 (2017). DOI: 10.1134/S1070427217030065]

[34] А.А.Нечитайлов, Н.В. Глебова, А.О. Краснова. ЖСХ, 60 (9), 1567 (2019). DOI: 10.26902/JSC_id46206 [A.A. Nechitailov, N.V. Glebova, A.O. Krasnova. J. Structur. Chem., 60 (9), 1507 (2019). DOI: $10.1134 / \mathrm{S} 0022476619090166]$ 